\title{
Postictal MRI features with a unilateral pattern
}

\author{
Alterações pós-ictais com distribuição unilateral na RM \\ Vanessa Dinoá, Felipe von Ranke, Emerson Gasparetto, Edson Marchiori
}

A 14-year-old female presented with focal seizure and secondary generalized convulsive status epilepticus lasting 2 hours. Electroencephalography revealed diffuse slow waves. Magnetic resonance imaging performed 2 days after onset demonstrated cortical swelling, gyri effacement, and restricted diffusion affecting the right temporal and parietal lobes (Figure). The differential diagnosis of these abnormalities included infarction, ischemia, venous thrombosis, vasculitis, infection, neoplasm, and metabolic encephalopathy. Because imaging findings were resolved completely after 38 days without specific treatment aside from supportive seizure therapy, infarction, venous thrombosis, vasculitis, infection, and neoplasm became less likely. Seizure-induced transient cerebral swelling was the most probable diagnosis ${ }^{1,2,3}$.
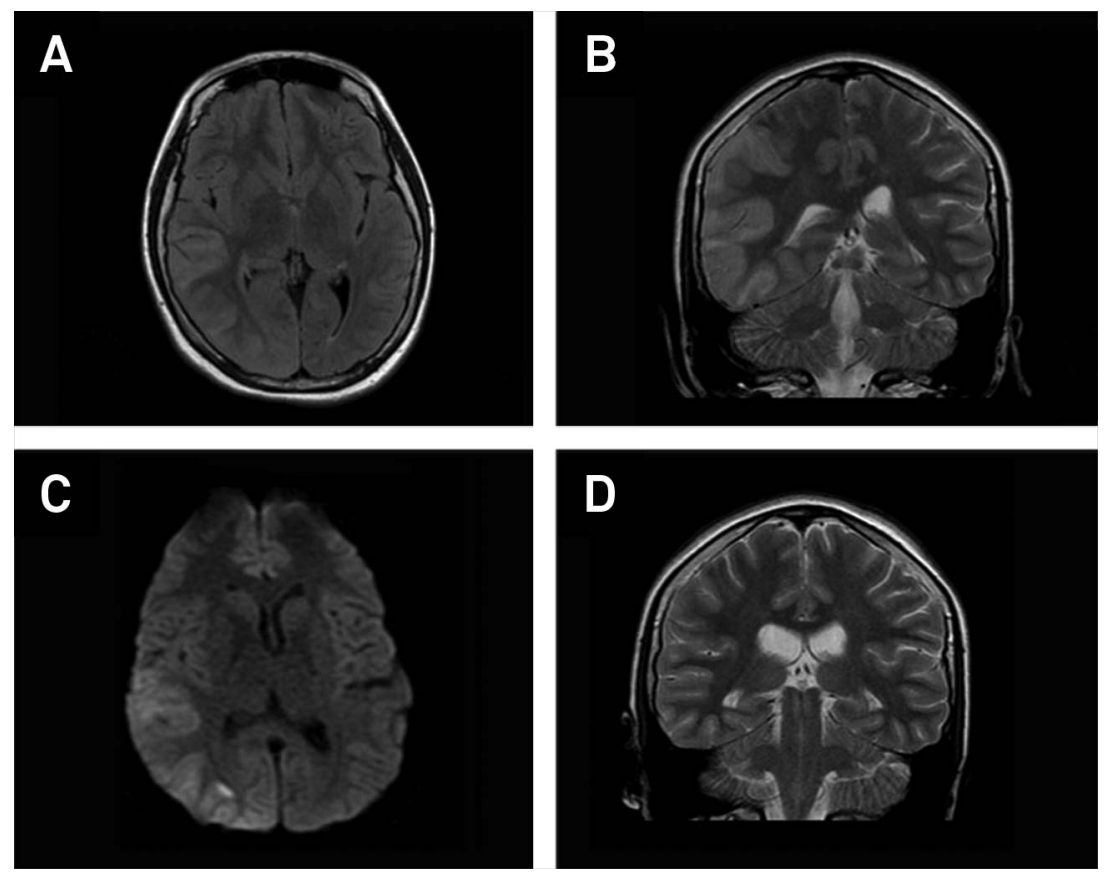

Figure. (A) Axial FLAIR and (B) coronal T2-weighted images show cortical swelling and gyri effacement in the right temporal and parietal lobes, with a mass effect over the right lateral ventricle; (C) DWI image shows restricted diffusion in this region; (D) Coronal T2-weighted images taken 38 days after onset show no initial feature or sequela.

\section{References}

1. Huang $Y C$, Weng HH, Tsai YT, Huang YC, Hsiao MC, Wu CY et al. Periictal magnetic resonance imaging in status epilepticus. Epilepsy Res. 2009;86(1):72-81. http://dx.doi.org/10.1016/j.eplepsyres.2009.05.011

2. Rémi J, Vollmar C, Marinis A, Heinlin J, Peraud A, Noachtar S. Congruence and discrepancy of interictal and ictal EEG with MRI lesions in focal epilepsies. Neurology. 2011;77(14):1383-90. http://dx. doi.org/10.1212/WNL.0b013e31823152c3

3. Kim JA, Chung JI, Yoon PH, Kim DI, Chung TS, Kim EJ et al. Transient MR signal changes in patients with generalized tonicoclonic seizure or status epilepticus: periictal diffusion-weighted imaging. AJNR Am J Neuroradiol. 2001;22(6):1149-60. 